www.jmscr.igmpublication.org

Impact Factor 5.84

Index Copernicus Value: 83.27

ISSN (e)-2347-176x ISSN (p) 2455-0450

crossref DOI: https://dx.doi.org/10.18535/jmscr/v5i4.101

Journal Of Medical Science And Clinical Research

\title{
Role of Interlocking Intramedullary Nailing in the Management of Unstable Fractures of Tibia by Using Medial Entry Point by Retracting Patellar Tendon Laterally
}

\author{
Authors \\ Mohamed Zubair ${ }^{1}$, Alfred Sathiya Sekar ${ }^{2}$, Noorul Ameen ${ }^{3}$, Minu $^{4}$, Praveena ${ }^{5}$ \\ ${ }^{1,2}$ Assistant Professor, Department of Orthopedics, Kanyakumari Medical College \\ ${ }^{3}$ Post Graduate, Department of Orthopedics, Sri Balaji Medical College, Chennai \\ ${ }^{4,5}$ Intern, Department of Orthopedics, Kanyakumari Medical College
}

\begin{abstract}
Background: Tibial fractures are most common fractures encountered in road traffic accidents due to its location. The aim of treating tibial fractures is to provide functionally useful and stable extremity. Among various treatments interlocking intramedullary nailing proves to be good.

Methods: In this study to highlight the role of interlocking intramedullary nailing by patellar tendon splitting approach in the management of unstable fractures of tibia, we have enrolled all the tibia fractures admitted in the orthopedics department in the time period of January 2016 to December 2016. It is prospective study.

Results: Among the patients studied 95\% were male patients, one was female [50\%]. Road traffic accidents were the common mode of injury (65\%), with fall (25\%) and assault (10\%) next in frequency. Right leg was found to be more prone for injury(80\%). Middle third fractures $(65 \%)$ contributed to maximum number of fractures.

Oblique (40\%) and communited (20\%) fractures were found in majority of cases. We followed anatomical and unstable fracture classification in our study. Majority of the cases were operated within 2 weeks of injury. Average duration between injury and operation is 9.5 days in our series. All cases were operated under spinal anesthesia over a simple radiolucent table with leg hanging by the side or by using wooden bolster or by bringing the patient at the edge of table. Tourniquet was used for all the cases. Our study included 95\% closed fractures, which healed in a mean time of 16.4 wks while open fracture (Grade I) united at an average duration of 20 wks. There were 4 cases with associated fractures. One patient had Ipsilateral open fracture femur with both bones leg lower third. Two of our patients had associated tibial plateau and fracture both bones in another leg. one patient had pelvic fracture. All patients were mobilized as early as possible, and weight bearing was started depending on callus formation. Per operatively we had difficulty in distal locking in two patients. $95 \%$ of the patients were locked in static mode. $90 \%$ of cases united normally and one had delayed union. Average duration for union in our study was 17 weeks.

Conclusion: Intramedullary interlocking nailing by medial entry point by retracting patellar tendon laterally has good functional outcome, low complication, early recovery when compared to other methods in stabilization of unstable tibial fractures.
\end{abstract}




\section{Introduction}

As the urbanization and industrialization is progressing with time and in this fast world with rapid increase in traffic, the incidence of high energy trauma are also increasing. Fractures of tibia are one of the most common injuries sustained during these accidents and are difficult to treat.

Because of its very location i.e., one third of its surface is subcutaneous throughout its length fractures are more common in tibia. Tibia has precarious blood supply due to inadequate muscular envelope and tibia fractures may be associated with compartment syndrome and neurovascular injuries. The presence of hinge joints at knee and ankle allow 110 adjustment for rotatory deformity after a fracture.

As in the case of other fractures, the goal of management of fractures of tibia is to bring back the patient to pre-diseased state. To achieve this aim fracture should be treated by effective, adequate fixation in appropriate time thereby allowing the patient to move neighboring joints without compromising the healing process. Thus movement and ambulation prevents the so called "Fracture disease" namely edema, swelling, pain and stiffness.

With the aim to achieve union and provide functionally useful and stable extremity, one has to choose the most appropriate treatment for particular pattern of injury. Treatment modalities available for tibial shaft fractures are closed reduction with long leg cast, open reduction and internal fixation with plates and screws, closed locked or unlocked intramedullary nails and external fixation techniques.

Surgeon should be well verse with all these treatment modalities and should weigh advantages and disadvantages before selecting the treatment modality. Without experience from some of the above mentioned types of treatment, the new way of thinking, reinforced by better biotechnology and instrumentation to achieve union of fracture in most anatomical position compatible with maximum functional return of the extremity leading to use of interlocking intramedullary nailing as the preferred method of treatment in tibial shaft fractures.

Charnley $^{2}$ in his text "Closed treatment of common fractures" said that, eventual solution to tibial shaft fractures would be non-reamed intramedullary nailing. The interlocking intramedullary nailing has become an attractive option after advent of $\mathrm{C}$ arm image intensifier. Nail is a load-sharing device and provides adequate strength for early weight bearing, axial micro motion and compression there by favoring early union. Closed intramedullary nailing involves least disturbance of soft tissue, fracture haematoma and natural process of bone healing. Locked nails provide maintenance of limb length, prevention of rotational instability and early mobilization.

The following study highlights the role of interlocking intramedullary nailing in the management of unstable fractures of the tibia by using medial entry point with patella tendon being retracted laterally and also to study procedure, outcome, advantages, disadvantages, sickness absenteeism and complications.

The aims and objectives of this study are

1. To study the effectiveness of interlocking intramedullary nailing in unstable tibial shaft fracture management.

2. To find out merits and demerits of procedure.

3. To Assess outcome of incision medial to patellar tendon by retracting the tendon 20 mm laterally.

4. To study the average time for fracture union.

5. To study the complications associated with the procedure and outcome.

6. To study period of sickness absenteeism.

\section{Materials and Methods}

Our study included Thirty four cases of fractures of shaft of tibia admitted in department of Orthopedics, Kanyakumari medical college, 
Asaripallam among, which 20 cases were unstable fractures of the Tibia treated with Interlocking intramedullary nailing by medial entry point. The study period was between January 2016 to December 2016.

\section{Choice of Nails}

Pre - operatively nail length was measured clinically from tibial tuberosity to the tip of medial malleolus of the unaffected tibia and 2.5 $\mathrm{cm}$ was subtracted from the measured length so that nail comes to lie within $2 \mathrm{~cm}$ of distal articular surface of tibia and to provide maximum fixation ${ }^{1}$. Nail diameter was calculated by measuring the diameter of medullary canal at the narrowest part i.e. isthmus. Accordingly a stock of interlocking nails of size, $2 \mathrm{~cm}$ above and below the measured length and $1 \mathrm{~mm}$ above and below the diameter measured were kept ready.

Operative technique [Procedure]

All of our patients were operated under spinal anesthesia. A simple radiolucent operating table was used for the procedure with patient brought to the edge of table and affected leg hanging by the side of table during procedure with knee flexed to $90^{\circ}$ or with hinged knee Bolster. This position of the limb is useful during reduction of the fracture and also during nail insertion using Jig.

A curvilinear Para patellar incision of about 5-8 $\mathrm{cm}$ was taken medial to patellar tendon and was retracted laterally. Using curved bone awl, medullary canal was opened in midline or slightly medially proximal to tibial tuberosity (about 1 $1.5 \mathrm{~cm}$ distal to joint line). Care is taken not to injure articular surface of tibia by not placing entry portal too proximally. Too distal placement of entry site may cause entry in to tibia at a steep angle either splitting the tibia anteriorly or breaking out through the posterior cortex. Thus by making sure that the entry portal is in center of medullary canal malalignments can be prevented. Entry portal was deepened by rotatory motion of awl and use of rigid reamer. A $3 \mathrm{~mm}$ guide wire was passed in to proximal fragment. Closed reduction of fracture was done and was confirmed and under guidance of image intensifier. Guide wire was passed in to distal fragment until it is 0.5 to $1 \mathrm{~cm}$ proximal to ankle joint.

Pre - selected nail was assembled to hexagonal bolt and proximal aiming devise so that aiming device directed medially with concavity of nail facing anteriorly.

Nail was driven over the guide wire in to the tibia till it reaches distal fragment with gentle blow over drive head using mallet. Knee was kept in flexion during insertion. skin and soft tissues were protected using tissue protector, and fracture was kept reduced when nail was passed in to distal fragment. Before final seating of nail, guide wire was retracted to prevent incarceration. Nail is driven until its proximal tip is flush with the tibia1 entry portal.

For proximal and distal locking we used $4.5 \mathrm{~mm}$ or $3.5 \mathrm{~mm}$ self tapping bolts depending on nail size $^{3}$. We in our institution performed distal locking first using free hand technique after perfect circles of locking holes were obtained on image intensifier. Use of same size interlocking nail as master nail helped us to localize approximate level of distal interlocking hole. This reduces radiation exposure during the procedure. Once the hole was located using $3 \mathrm{~mm} \mathrm{~K}$ - wire, stab incision was made retracting soft tissues, An impression was made over near cortex which was later drilled with $3.5 \mathrm{~mm}$ drill bit. Correct entry of $\mathrm{K}$ - wire or drill bit in the hole was confirmed by hitting the in situ $\mathrm{K}$ - wire with intramedullary guide which will produce metallic sound and moves the wire confirming its position within the nail. After far cortex is also drilled distal locking screw (bolt) was inserted; after measuring screw length using depth gauge.

For proximal locking, $8 \mathrm{~mm}$ drill sleeve and trocar were used. A stab incision was made at the impression made by trocar. Trocar was removed and $4 \mathrm{~mm}$ drill sleeve was inserted and tibia was drilled from medial to lateral using $3.5 \mathrm{~mm}$ drill bit. Required size of bolt was measured and locking bolt was inserted using hexagonal screwdriver. In our study we have routinely 
performed static locking with at least one bolt each proximally and distally. In stable transverse fractures we have used vertical slot among proximal holes for locking. Positions of locking bolts were confirmed on image intensifier.

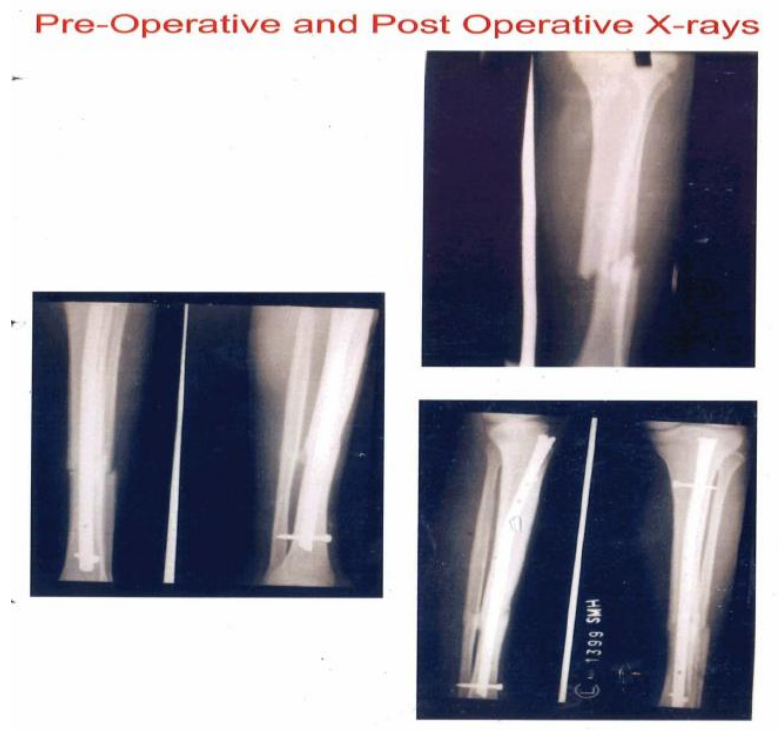

Implant Design ${ }^{3}$

In this study we have used A.0 Interlocking Intramedullary nails. This nail is tubular hallow nail with wall thickness of $1.2 \mathrm{~mm}$. This nail is available in 7, 8, 9 and 10mm diameters. Tanna nail (Indian type) is suitable for Indian population who are short with narrow medullary canal. Nail has got two proximal and two distal locking holes. For 7 and $8 \mathrm{~mm}$ diameter nails $3.5 \mathrm{~mm}$ bolts were used, and for 9 and $10 \mathrm{~mm}$ nails. $4.5 \mathrm{~mm}$ bolts were used. Proximal locking holes are directed medio laterally. Proximal locking holes arc situated $3 \mathrm{~cm}$ from the Herzog bend. One of these two holes can be a vertical slot allowing for compression at fracture site.Nails are threaded proximally for hexagonal bolt attachment and slots on either side to accommodate projection in the Jig, which prevent rotation of nail. Other interlocking nails commonly used are G - K tibial nail, Russell Taylor tibial Nail.

\section{Observation and Results}

The present study includes 20 patients with unstable fracture shaft of tibia among 34 patients admitted at Department of Orthopedics, Kanyakumari medical college, Asaripallam between Jan 2016 to Dec 2016. (The cases were followed up to union or further as and when required or at least for 6 months).

Table 1: Age and sex Distribution

\begin{tabular}{|l|c|c|c|c|}
\hline Age & Males & Females & Total & $\begin{array}{c}\text { Percentages (for } \\
\text { age) }\end{array}$ \\
\hline $18-27$ & 4 & - & 4 & 20 \\
\hline $28-37$ & 11 & 1 & 12 & 60 \\
\hline $38-47$ & 3 & & 3 & 15 \\
\hline $48-57$ & 1 & - & 1 & 5 \\
\hline & 19 & 1 & 0 & 0 \\
\hline
\end{tabular}

Graph 1: Age Distribution

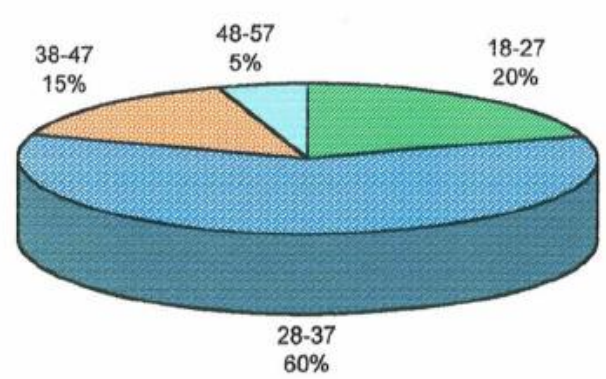

Out of 20 cases studied, 19 patients were male $(95 \%)$ only 1 was a female $(5 \%)$

Youngest in our study were 2 patients were below 20 years age and oldest was a male patient of 57 yrs. The mean age in our study was $30-40 \mathrm{yrs}$.

Table 2: Mode of injury

\begin{tabular}{|l|c|c|}
\hline Mode of injury & No. of patients & Percentage \\
\hline Road Traffic accident & 13 & $65 \%$ \\
\hline Fall & 5 & $25 \%$ \\
\hline Assault & 2 & $10 \%$ \\
\hline
\end{tabular}

Graph 2 : Mode of injury

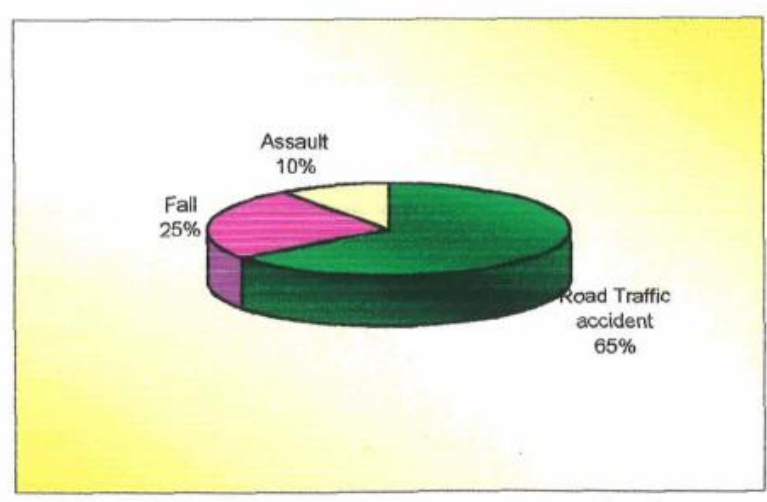

Majority of the patients had road traffic accidents as the mode of injury (65\%) 


\section{JMSCR Vol||05||Issue||04||Page 20357-20367||April}

Table 3: Side of fracture

\begin{tabular}{|l|c|c|}
\hline Side & No. of Patients & Percentage \\
\hline Right & 16 & 88 \\
\hline Left & 4 & $20 \%$ \\
\hline
\end{tabular}

Right leg was predominantly involved in majority of cases $(80 \%)$ while left leg was involved in $20 \%$ of cases.

Table 4: Level of fracture

\begin{tabular}{|l|c|c|}
\hline Level & No. of cases & Percentage \\
\hline Upper $3^{\text {rd }}$ & 1 & $5 \%$ \\
\hline Mid $3^{\text {rd }}$ & 13 & $65 \%$ \\
\hline Lower $3^{\text {rd }}$ & 6 & $30 \%$ \\
\hline
\end{tabular}

Graph 3: Level of fracture

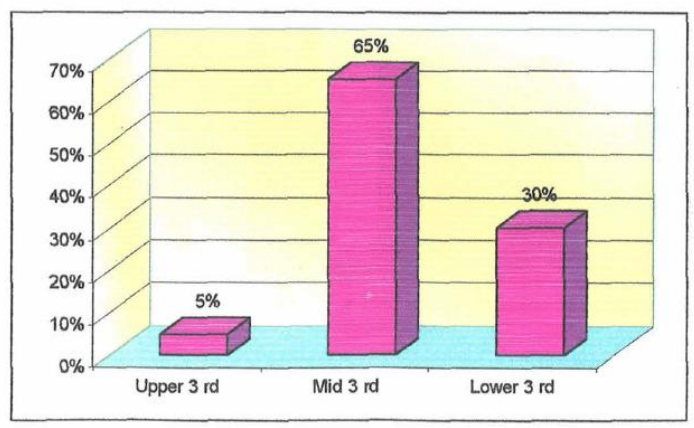

One fracture which at middles and lower third junction was included in middle third fractures. $65 \%$ of the total cases had mid $3^{\text {rd }}$ fractures. Low number of upper third fractures $(5 \%)$ was due to usual finding of higher level fracture or metaphysical extension found in most of the cases.

Table 5: Fracture Pattern/ Nature.

\begin{tabular}{|l|c|c|}
\hline Nature of Fracture & No. of cases & Percentage \\
\hline Transverse & 1 & $5 \%$ \\
\hline Oblique & 8 & $40 \%$ \\
\hline \# Tibia with intact fibula & 4 & $20 \%$ \\
\hline Comminuted & 4 & $20 \%$ \\
\hline Segmental & 3 & 15 \\
\hline
\end{tabular}

We in our study came across oblique fractures in $40 \%$ of patients and in 5\% transverse factures indicating three or four point bending mechanism is most commonly involved.

Table 6: Types of fracture

\begin{tabular}{|l|c|c|}
\hline Type & No. of cases & Percentage \\
\hline Closed & 19 & $95 \%$ \\
\hline Open $($ Grade I) & 1 & $5 \%$ \\
\hline
\end{tabular}

19 of our cases $(95 \%)$ were closed fractures and one open (Grade 1) $5 \%$

Table 7: Associated injuries.

\begin{tabular}{|l|c|}
\hline Associated Injuries & No. of cases \\
\hline $\begin{array}{l}\text { Ipsi-lateral femur fracture with both } \\
\text { bones leg lower third Right side }\end{array}$ & 1 \\
\hline Opposite both bones +Tibial plateau \# & 1 \\
\hline Fracture pelvis & \\
\hline Contra lateral both bones fracture & 1 \\
\hline
\end{tabular}

Our study had one patient with Ipsilateral open (Grade 1) fracture shaft of femur $\left(\mathrm{L} / 3^{\text {rd }}\right)$ with both bores leg in lower third Who was treated with delayed plating for femur and Interlocking nail for both bones of leg Right side. Femur fracture healed in 10 weeks time. In our series no other system injuries were encountered. Two patients had both bones both leg fracture .One patient had associated Tibia1 plateau fracture. one patient had pelvic fracture.

Table 8: Duration between injury and operation.

\begin{tabular}{|l|c|c|}
\hline Duration & No. of cases & Percentage \\
\hline$\leq 1$ Week & 9 & $45 \%$ \\
\hline $1-2$ weeks & 8 & $40 \%$ \\
\hline $2-3$ weeks & 2 & $10 \%$ \\
\hline$\geq 3$ weeks & 1 & $5 \%$ \\
\hline
\end{tabular}

Graph 4: Duration between injury and operation.

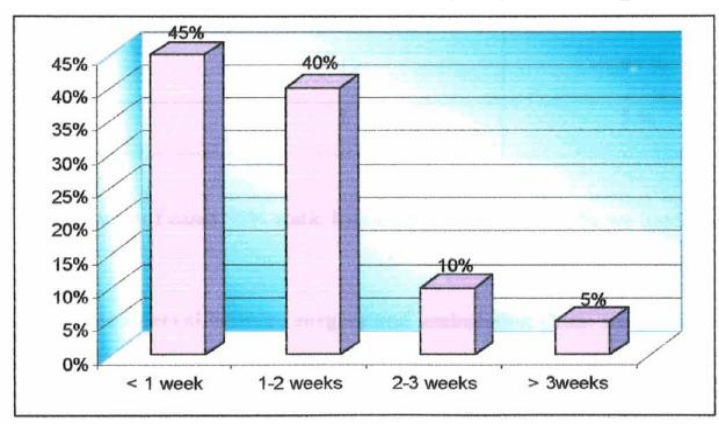

$45 \%$ of the selected cases were operated electively in first week of their injuries and $40 \%$ in second week. Three cases which were operated late because they came to hospital late ( either referred late after visiting a local osteopath).

Table 9: Difficulties during operation

\begin{tabular}{|l|c|}
\hline Difficulties & No. of cases \\
\hline Difficult reduction & - \\
\hline Difficulty in distal locking & 2 \\
\hline
\end{tabular}




\section{JMSCR Vol||05||Issue||04||Page 20357-20367||April}

During procedure we experienced difficulty in distal locking in two cases. One patient had missed distal locking.

Table 10: Mode of locking

\begin{tabular}{|l|c|c|}
\hline Mode of locking & No. of Cases & Percentage \\
\hline Static & 19 & $95 \%$ \\
\hline Dynamic & 1 & $5 \%$ \\
\hline
\end{tabular}

In majority of cases $95 \%$ static locking was used and in 5\% we used dynamic Locking.

Table 11: Time interval between surgery and ambulation (Non- weight bearing)

\begin{tabular}{|l|c|c|}
\hline Time interval (wks) & No. of patients & Percentage \\
\hline$<1$ Week & - & $45 \%$ \\
\hline $1-2$ weeks & 15 & $30 \%$ \\
\hline $2-3$ weeks & 4 & $20 \%$ \\
\hline$>3$ weeks & 1 & $5 \%$ \\
\hline
\end{tabular}

Graph 5. Time interval between surgery and ambulation (Non-weight bearing)

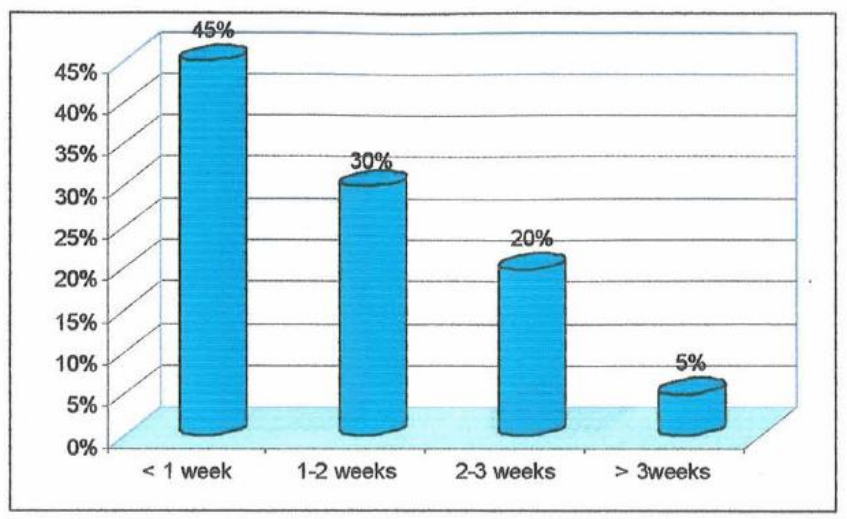

We routinely started the patients on non - weight bearing mobilization between 1 - 2 weeks after sutures are removal. Within $1^{\text {st }}$ week patient was advised knee and ankle movements.

Table 12: Time for union

\begin{tabular}{|l|c|c|}
\hline Time for union $(w k s)$ & No. of cases & Percentage \\
\hline $10-20$ (Normal) & 19 & $95 \%$ \\
\hline$>20$ (Delayed) & 1 & $5 \%$ \\
\hline
\end{tabular}

Graph 6: Time for union

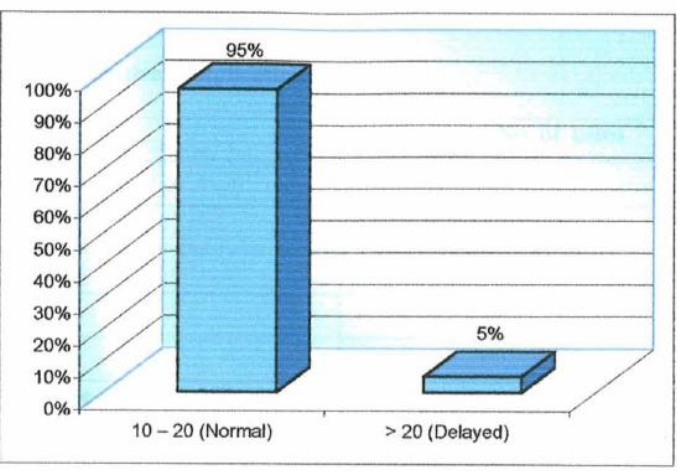

Table 13: Union in relation to types of fractures

\begin{tabular}{|l|c|}
\hline Type of fracture & Average time for union (in weeks) \\
\hline Closed & 16.4 weeks \\
\hline Open $($ Grade 1$)$ & 20 weeks \\
\hline
\end{tabular}

Table 14 : Union in relation to level of fracture

\begin{tabular}{|l|c|}
\hline Level of fracture & Average time for union (in weeks) \\
\hline Upper third & 16 weeks \\
\hline Middle third & 16.7 weeks \\
\hline Lower third & 17.83 weeks \\
\hline
\end{tabular}

In present study, 19 fractures united with average time for union being 17 wks. One patient with open (Gr. 1) fracture treated with static locking had delayed union.

This patient came only twice for follow up. Closed Tibial fractures united at an average of 16.4 wks and open fractures at an average of 20 wks. There was no significant difference between union time for middle and lower third fractures.

Table 15: Post operative complications

\begin{tabular}{|l|c|}
\hline Complications & No. of cases \\
\hline Superficial & 1 \\
\hline Deep infection & 1 \\
\hline Delayed union & 1 \\
\hline Non union & 0 \\
\hline Malunion & 0 \\
\hline Restriction of knee motion $>25^{0}$ & 2 \\
\hline Restriction of ankle motion $>15^{0}$ & 2 \\
\hline Shortening & 0 \\
\hline Significant knee pain & 0 \\
\hline
\end{tabular}

Among 20 cases done using Tibial medial entry point by retracting patellar tendon laterally. One patient had anterial knee pain and extensor lag. One patient had extensor lag alone. 


\section{JMSCR VoI||05||Issue||04||Page 20357-20367||April}

Criteria for Assessment of the Result ${ }^{5 .}$

EKELANDS CRITERIA ${ }^{5}$ :

\begin{tabular}{|c|c|c|c|c|}
\hline & Excellent & Good & Fair & Poor \\
\hline Tibial malalignments and shortening & & & &. \\
\hline Varus or valgus & $2.5^{\circ}$ & $5^{\circ}$ & $10^{\circ}$ & $>10^{\circ}$ \\
\hline Antecurvatum or recurvatum & $5^{0}$ & $10^{\circ}$ & $15^{\circ}$ & $>15^{\circ}$ \\
\hline Internal rotation & $5^{\circ}$ & $10^{\circ}$ & $15^{\circ}$ & $>15^{\circ}$ \\
\hline External rotation & $10^{\circ}$ & $15^{\circ}$ & $20^{\circ}$ & $>20^{\circ}$ \\
\hline Shortening & $1 \mathrm{~cm}$ & $2 \mathrm{~cm}$ & $3 \mathrm{~cm}$ & $>3 \mathrm{~cm}$ \\
\hline \multicolumn{5}{|l|}{ Range of knee motion } \\
\hline Flexion & $>120^{\circ}$ & $120^{\circ}$ & $90^{\circ}$ & $<90^{\circ}$ \\
\hline Extension deficit & $5^{\circ}$ & $10^{\circ}$ & $15^{\circ}$ & $15^{\circ}$ \\
\hline \multicolumn{5}{|l|}{ Range of ankle motion } \\
\hline Dorsiflexion & $>20^{\circ}$ & $20^{\circ}$ & $10^{\circ}$ & $<10^{\circ}$ \\
\hline Plantar flexion & $>30^{\circ}$ & $30^{\circ}$ & $20^{\circ}$ & $<20^{\circ}$ \\
\hline \multicolumn{5}{|l|}{ Foot motion as a fraction of normal } \\
\hline Range of motion & $5 / 6$ & $2 / 3$ & $1 / 3$ & $<1 / 3$ \\
\hline Pain & None & Sporadic & Significant & Severe \\
\hline Swelling & None & Minor & Significant & Severe \\
\hline
\end{tabular}

\section{Discussion}

The goals of treatment for tibial shaft fractured should include reestablishment of pre- injury anatomy and function in shortest possible time with. negligible complication rate. Tibia being one of the commonly fractured and reproducible methods of treatment which helps to achieve above mentioned goal. Treatment for unstable fracture by closed intramedullary inter locking nailing with patella tendon retracted laterally seems to be the answer.

Most tibial fractures can be treated by closed reduction and casting especially low energy fracture

Our series included study of 20 unstable Tibia 1 shaft fractures treated by Interlocking intramedullary nailing using patellar tendon retracted laterally. Open injuries on admission were irrigated, cleaned and dressed. We followed the unstable fractures of tibial classification indicating the pattern of fracture. Oblique, spiral, comminuted, fracture tibia middle third with intact fibula and segmental fractures are grouped in unstable fractures. All the fractures were treated by closed interlocking intramedullary nailing with patellar tendon being retracted laterally. We could follow closed method in all fractures. Even in fractures which were fixed later than 4-5 days were imniobilized by calcaneal traction to maintain the length. Also in fractures with significant overlap were put in calcaneal traction. All 20 patients were operated under spinal anesthesia.

Unreamed nailing has the advantages in the form of minimal endosteal vascular damage, decreased operative time, avoidance of complications from reaming like compartment syndrome, pulmonary embolism. Reaming of medullary canal further damages the already compromised blood supply of tibia. There can be sequestration of endosteal surface of cortex due to micro embolization secondary to reaming. It is believed that $71 \%$ of cortical blood supply is compromised by reaming the medullary canal due to embolization as well as heating effect. (Kessler 1986)". Subcutaneous nature of tibial shaft provides only a thin coverage of vascularized soft tissue, increasing the risk of non-union and deep infection. Disadvantages of nailing without reaming include use of smaller diameter nail which may not uniformly and snuggly fit in to medullary canal. Reaming medullary canal has the advantage of choosing a larger diameter nail and bolt which help in early weight bearing. The reamed material has osteoinductive properties which help in union by abundant callus formation.

In our series $95 \%$ of patients were male and majority of them were young i.e. $75 \%$ were within the age of 37 years. Road traffic accident was the commonest mode of injury in $75 \%$ of patients indicating propensity of young patients for road traffic accident. $65 \%$ of the patients had fracture of right tibia.

As the majority of cases were secondary to RTA, many of the upper third and lower third fractures which were admitted had intra-articular extension or not fitting in to criteria for inter locking nailing and hence had to be left out. $65 \%$ of the fractures in our study were mid third fractures.

In our study we followed unstable fracture tibia classification indicating the pattern of fracture. 
We had $35 \%$ transverse fractures, $40 \%$ oblique fractures, $15 \%$ were spiral fractures and $10 \%$ had comminuted fractures. There were no segmental fractures. Road traffic accidents were responsible for majority of oblique and spiral fractures. In our series, middle third fractures healed at an average time of 16.7 weeks, upper third at 16 weeks and lower third at 17.83 weeks. In similar study by Court Brown ${ }^{6}$ and colleagues achieved union in mid third fractures at an average of 16.7 weeks, distal third at 18.2 weeks and proximal third at 16.2 weeks.

Table 17: Fracture union in relation to level of fracture

\begin{tabular}{|c|c|c|}
\hline Level & Our series & Court-Brown \\
\hline Upper $3^{\text {rd }}$ & 16 weeks & 16.2 weeks \\
\hline Middle $3^{\text {rd }}$ & 16.7 weeks & 16.7 weeks \\
\hline Lower $3^{\text {rd }}$ & 17.83 weeks & 18.2 weeks \\
\hline
\end{tabular}

As evident from above studies there was no significant difference in healing at different levels. Statistically observed difference in union time of middle third and lower third fractures is nonsignificant $\left(\mathrm{t}_{\mathrm{cal}}=0.8731 ; \mathrm{DF}=16 ; \mathrm{P}=0.05 \mathrm{NS}\right)$. Healing in proximal and distal third fractures is avoided by metaphysial vessels which help in early revascularization.

Ninety five percent of fractures were closed fractures and 5\% were open fractures (Grade I). On admission wound was washed by irrigating, cleaning and dressing was done. Patient was immobilized in calcaneal traction or above knee pop slab. Open fractures were classified according to Gustilo Anderson Classification. Closed fractures in our series healed at an average of 16.4 weeks and open fractures at an average of 20 weeks. We had superficial infection with delayed union in one patient which healed with secondary suturing and control of infection by appropriate antibiotics. Three patients had associated orthopedic injuries, one patient has Ipsilateral open (Grade-I) fracture shaft of femur in lower third with fracture both bones leg in lower third for which he was treated with plating for femur and Interlocking nailing treatment for tibia. Tibia healed in 13 weeks time. Femur fracture progressed to infected non- union. This led to delayed ambulation of patient who was ambulated at 24 weeks after plate removal. All of our cases were operated electively on elective operation day. Average duration between injury and operation was 9.45 days varying between 3 days and 30 days. Most of the cases reached hospital late after injury. Only11 of the 20 cases were operated within 1 week of injury. Remaining was operated between 8 days - 30days. No patient was operated on the day of admission. In our study we have used A0 variety of interlocking intramedullary nails.

All the cases were operated using a Para medial incision and retracting patellar tendon laterally to make entry portal. This approach decreases knee pain which is common with patellar tendon splitting approach. Patellar tendon splitting approach can also cause extensor lag in some of the patients.

In our study, we have used $8 \mathrm{~mm}, 9 \mathrm{~mm}$ and 10 $\mathrm{mm}$ diameter nails. 19 fractures were locked in static mode and 1 in dynamic mode. We did not routinely dynamize the static locked nails.

In two cases we had difficulty in distal locking. In this series ankle and knee motion exercise were started as early as 3 - 4 days post operatively in absence of associated injuries. 111 majority of cases i.e. $75 \%$ of cases (15 patients) non- weight bearing crutch 1 walker ambulation was started by 2 weeks and between 2-4 weeks in 20\% (4 cases), after 4 weeks in 5\% (1 patient). Main reason for delayed ambulation was associated injuries which prohibited early ambulation. Partial weight bearing was allowed when callus was seen around the fracture. Full weight bearing was started after clinical and radiological union. By following this protocol we were able to avoid complication of implants failure in the form of screw breakage by avoiding over enthusiastic weight bearing. Although nails are load sharing devices and some amount of weight bearing is advised as it will help in union by causing micro motion at the fracture 
site but with full weight bearing there is always a risk of implant failure with time ${ }^{2}$.

We started partial weight bearing for 15 patients $(75 \%)$ by $6^{\text {th }}$ post operative weeks. Of the remaining patients,in 3 patients had associated injuries for them weight bearing was delayed. In 2 patients, delay was due to presence of comminution. Weight bearing was started when primary callus was evident on X-ray. In our series 95\% (19 cases) united by 20 weeks. There was 1 case $(5 \%)$ of Delayed union. This patient did not come for follow up after discharge. Average time for union in our series was 17 weeks. On comparison with standard study (Gregory and sanders) observe difference is less than twice the SE p-p (1 8.84) and the difference is nonsignificant.

Table 18: Average duration for union(compared with other studies)

\begin{tabular}{|l|c|}
\hline Study & $\begin{array}{c}\text { Average duration } \\
\text { in weeks }\end{array}$ \\
\hline $\begin{array}{l}\text { C.M Court - brown et al } \\
\text { (Close and Gr-1 open, reamed) }\end{array}$ & 16.7 weeks \\
\hline $\begin{array}{l}\text { p. Gregory and R. Sanders } \\
\text { (Closed and un reamed) }\end{array}$ & 16.0 weeks \\
\hline $\begin{array}{l}\text { G. Hooper et al } \\
\text { (closed and Gr-1 open) }\end{array}$ & 15.7 weeks \\
\hline $\begin{array}{l}\text { C.A. Muller et al. } \\
\text { (closed and un reamed ) }\end{array}$ & 16 weeks \\
\hline Current series & 17 weeks \\
\hline
\end{tabular}

Amount of malalignments and shortening considered acceptable is also controversial. According to Traftons recommendations ${ }^{1}$ less than $5^{0}$ of Varus or valgus angulation, $10^{\circ}$ anteroposterior angulation, less than $10^{\circ}$ of rotation and less than $15 \mathrm{~mm}$ of shortening are acceptable.

But according to Rockwood-Green ${ }^{2}$, acceptable limits are $5^{0}$ of Varus or valgus angulation, $10^{\circ}$ of antero-posterior angulation, less than $10^{\circ}$ of rotation with reference to opposite extremity and 1 $\mathrm{cm}$ or less for length discrepancy. We have followed these criteria for acceptable limits. We in our series did not have any significant malalignment. We followed Ekelands criteria ${ }^{4}$ for assessment of functional results. We had 95\% good excellent results and 5\% were poor results among which one was a case of infection with delayed union.

Table 19: Comparison of Results

\begin{tabular}{|l|c|c|c|c|}
\hline & $\begin{array}{c}\text { Our } \\
\text { series }\end{array}$ & $\begin{array}{c}\text { Anti. Alho } \\
\text { et al }\end{array}$ & $\begin{array}{c}\text { Gregory } \\
\text { Senders }^{20}\end{array}$ & $\begin{array}{c}\text { A.Ekeland } \\
\text { et al. }^{5}\end{array}$ \\
\hline Excellent & $70 \%$ & $68.4 \%$ & $50 \%$ & $64.4 \%$ \\
\hline Good & $20 \%$ & $23.36 \%$ & $29 \%$ & $28.85 \%$ \\
\hline Fair & $5 \%$ & $11.8 \%$ & $5 \%$ & $4 \%$ \\
\hline Poor & $5 \%$ & $2.2 \%$ & $16 \%$ & $2 \%$ \\
\hline
\end{tabular}

A. Alho et al. ${ }^{8}$ treated 93 fractures of tibial shaft (closed, grade I and II open) with Gross - Kempf locked nail. The result was excellent in 58 fractures $(62.4 \%)$ good in $22(23.6 \%)$ fair in 11 $(11.8 \%)$ and poor in two $(2.2 \%)$. Timing of operation did not affect course or result and also open fracture results did not differ from closed fractures. Median time for union was 16 weeks for comminuted and 14 weeks for others.

In our series there was one case of Delayed union. D. Aubigne M.R. et $\mathrm{a} 1{ }^{9}$ had Malunion in $1 \%$ of fracture treated by nailing. They found that alignment is usually good in the middle and lower part with $4 \%$ deviation under 10 degrees and $0.3 \%$ deviation to 10 degree. It is less satisfactory in upper shaft and near the bone ends when they found $16 \%$ deviation less than 10 degree and $5 \%$ greater than 10 degree.

Paul Gregory and Roy Sanders ${ }^{1}$ treated 38 fractures with Un reamed interlocking nails. 87\% of fractures healed within 6 months. All patients had normal knee, ankle and subtalar joint movements. There were $2(5 \%)$ delayed union, $3(.98 \%)$ non unions. Three patients $(8 \%)$ had angular deformities. There was $2.6 \%$ of superficial infection (I case) $2.6 \%$ Osteomyelitis.

They concluded that high union rate, coupled with a lack of compartment syndrome or peroneal nerve palsy makes this procedure attractive. C.M. court- Brown, J. Chrostic, M.M. Mc Queen ${ }^{7}$ Presented results of use of Grosse - Kempf inter locking nail in the management of 125 closed and type I open Tibial fractures. The mean time to union was 16.7 weeks. No fracture required bone grafting. Mobilization of patient and range of joint movements were better than with other methods 
of treatment. There was $1.6 \%$ incidence of infection, $40.8 \%$ of patients had knee pain and $26.4 \%$ needed to have nail removed. There was $1.6 \%$ of non union. Unacceptable deformity or shortening occurred in $2.5 \%$ of patients. Klemm and Borner $^{10}$ reported $40 \%$ tibial fractures 308 closed and 93 grade I open (delayed nailing) 81\% of fractures were potentially unstable to shortening and rotation. $77 \%$ were nailed in static locking configuration and $23 \%$ were nailed in dynamic locking configuration. Closed nailing was possible in 98\% fractures of 267 fractures reviewed, $94 \%$ had excellent or good results. There was $2.2 \%$ deep infection which responded to antibiotic treatment.

One patient who had developed superficial infection progressed to delayed union. Infection subsided with antibiotics administration. A case of ipsilateral compound shaft femur with fracture both bones leg had significant restriction of knee and ankle movements. Thus the amount of adjacent joint movements regained also depends on the associated fractures. Parapettalar approach maintains blood supply to pettalar and does not affect the anatomy of quadriceps tendon. So in parapatellar approach the stability of knee is maintained.

\section{Conclusion}

1) Medial Parapetallar approach has low incidence of anterior knee pain.

2) No extensor lag in these patients.

3) Climbing stairs and squatings are earlier in these patients

4) Closed interlocking intramedullary nailing promotes early union as it does not further compromise vascularity of fracture site and does not disturb, fracture haematoma.

5) Interlocking nailing has advantage over cast treatment in the form of short hospital stay, early ambulation and minimal or no joint stifiess.

6) Low complication rate with better rotateonal control of fragments as compared with unlocked intramedullary nails.
7) Has minimal blood loss.

8) Associated with low risk of infection.

9) Early mobilization reduces fracture disease and reduces sickness absenteeism.

10) Unreamed nailing has low incidence of compartment syndrome, Peroneal nerve palsy and is acceptable in open fracture as against reamed nailing.

11) Unreamed nailing has disadvantage of using thinner nails hence delay in weight bearing compared with reamed nailing.

Hence closed interlocking intramedullary nailing with patella tendon being retracted laterally is an efficient method of stabilization of unstable fractures of tibia.

\section{References}

1. Nicoll, E.A.; closed and open management of; tibial fractures; Clin Orthop; 105; 1974; 144-153.

2. Thomas . A. Russel. Fractures of Tibia and fibula; Rock wood \& green's Fractures in Adults ; Fourth Edition ; 2nd volume, pp 2127 - 2199 ; 'Philadelphia, J.B. Lippin cott, 1996.

3. Tanna D.D, ; Brief report ; Interlocking tibial nailing without image intensifier; J. Bone Joint Surgery ; 1994 ; 76B ; 670

4. Ekeland A. Et al. Interlocking intramedullary nailing in the treatment of tibia fractures; clinical orthop; 1988; 231; pp $205-216$.

5. Sermiento et a1 ; Tibial shaft; fractures treated with functional braces J. Bone Joint surg. 71 B ; 602 - 609, 1989

6. C. M. Court - Brown, J. Christie, M. M. Mc Queen; closed intramedullary tibial nailing; The journal of Bone and joint surgery; 1990; 79.B : 605-611

7. Muller C.A. Strolum P. Morakis, P, Pfister; intramedullary nailing of the tibia; current status of primary unreamed nailing Part - 1 results for closed fractures; Injury Int. J. care of injured 1999; S.C-37 -S.C 43 
8. A. Alho Arne. Ekeland; Knut Stromsoe; Gunnar Folleras, Bjom Olavatheresen; Locked intramedullary nailing for displaced tibial shaft fractures J. Bone Joint Surgery; 72 - B ; 1990. ; 805 - 809

9. D'Aubugne, Maurer, Zachwan; Blind intramedullary nailing of tibial fractures; chin, Orthos; 1974 ; 105 ; pp 192.

10. Klemm W. R and Borner M; Interlocking nailing of complex fracture of femur and tibia; Clin Orthop; 1980; 212; 89 - 100 